\title{
Settlement characteristics of major infrastructures in Shanghai
}

\author{
X. Jiao ${ }^{1,2}$, X. X. Yan ${ }^{1,2}$, and H. M. Wang ${ }^{1,2}$ \\ ${ }^{1}$ Shanghai Institute of Geological Survey, Shanghai, China \\ ${ }^{2}$ Key Laboratory of Land Subsidence Monitoring and Prevention, Ministry of Land and Resources of China, \\ Shanghai, China \\ Correspondence to: X. Jiao (jiaoxun83@126.com) \\ Published: 12 November 2015
}

\begin{abstract}
Critical infrastructures in Shanghai have undergone uneven settlement since their operation, which plays an important role in affecting the security of Shanghai. This paper, taking rail transportation as example, investigates settlement characteristics and influencing factors of this linear engineering, based on long-term settlement monitoring data. Results show that rail settlement is related to geological conditions, regional ground subsidence, surrounding construction activities and structural differences in the rail systems. In order to effectively decrease the impact of regional ground subsidence, a monitoring and early-warning mechanism for critical infrastructure is established by the administrative department and engineering operators, including monitoring network construction, settlement monitoring, information sharing, settlement warning, and so on.
\end{abstract}

\section{Introduction}

Since the opening of Metro Line 1 in January 1990, a total of 11 rail lines have been put into operation in Shanghai, and the mileage has increased to $410 \mathrm{~km}$ in 2010 . These subway systems play a great role in relieving traffic congestion on the ground, which bring good social, economic and environmental benefits. However, the uneven settlement, caused by rail construction and operation, emerged in several lines, and resulted in negative impacts on rail safety and management(Chen and Zhan, 2000; Wang, 2009; Wang and Hang, 2004). In this paper, we surveyed plenty of long-term monitoring data for tract bed settlement, mostly coming from three lines (Lines A, B, C in the text), and drew up the settling characteristics and affecting factors for subway tunnels. Also the management for rail-settlement controls in Shanghai were introduced.

\section{Laws for rail settlement}

Of the three lines, Line A was the first to be put into operation, followed by Lines B and C.
From the monitoring results, Line A has a maximum cumulative settlement, of about $-111.1 \mathrm{~mm}$ from 1995 to 2010 . Figure 1 shows that two sedimentation bowls exist in Line A, from Site 260 to Site 340 and Site 560 to Site 780 . While Line B had an average cumulative settlement of $-57.9 \mathrm{~mm}$ from 1999 to 2010, and two intervals, from Site 480 to Site 1680 and Site 1860 to Site 2220 in Fig. 2, underwent larger settlement. However Line C exhibits a smooth trend in overall settlement, with a cumulative settlement of $-4.4 \mathrm{~mm}$ from 2008 to 2010 (Fig. 3).

According to the curves of Lines A and B (Figs. 2, 3), the tunnel sedimentation rate was much larger in the first few years, particularly in the bowl area whose settlement rate exceeded $20 \mathrm{mma}^{-1}$, then the rate gradually reduced to a smaller value and eventually transitioned to a stable state.

We compared the monitoring results of rail settlement and extensometer data, and found that the subsidence trend was consistent from the tunnel to the bedrock, and the soil compression below the tunnel floor played a controlling role in tunnel settlement. For example, results of Line A Site 782 shows a high level correlation with the settlement at the nearby extensometer from 1999 to 2010 (Fig. 4). At the end of 2010, Site 782 shows a cumulative settlement of about 


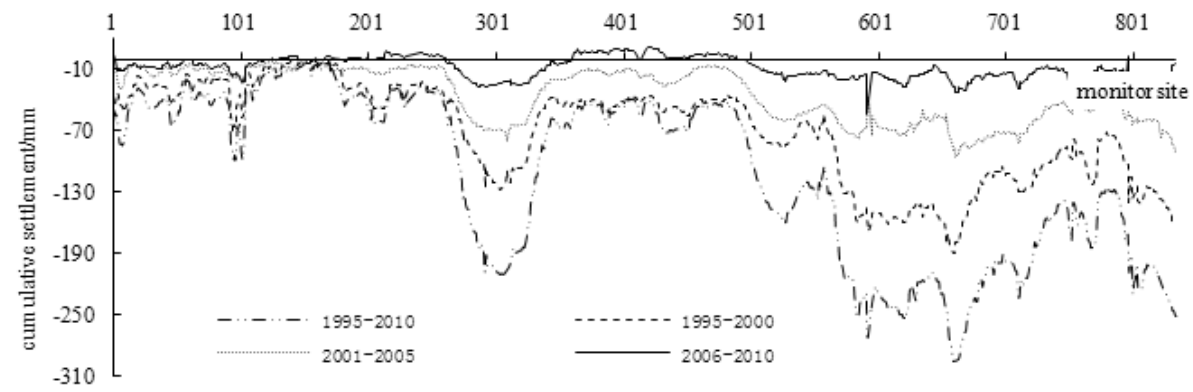

Figure 1. Graph of cumulative settlement of A in different periods

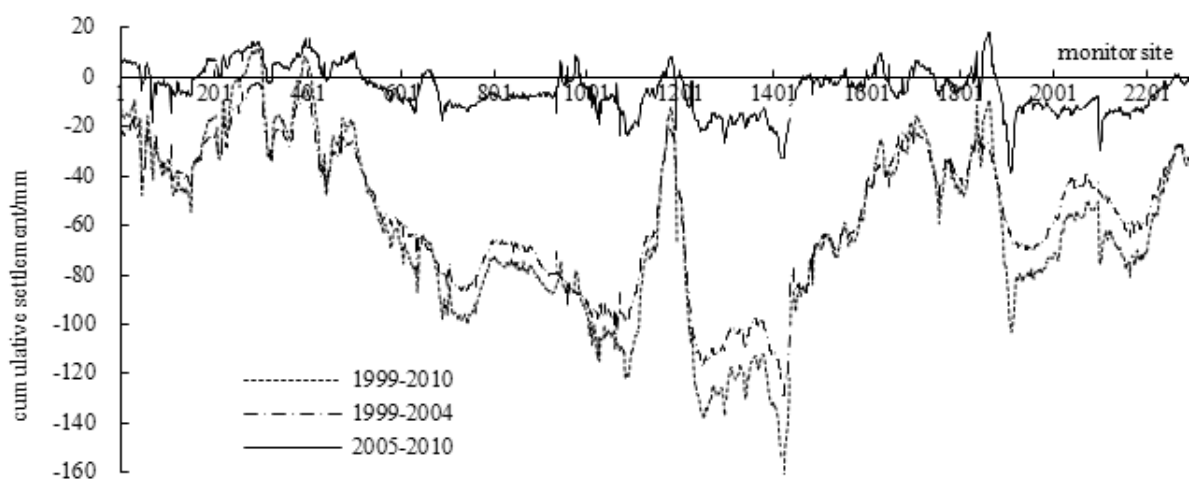

Figure 2. Graph of cumulative settlement of B in different periods.

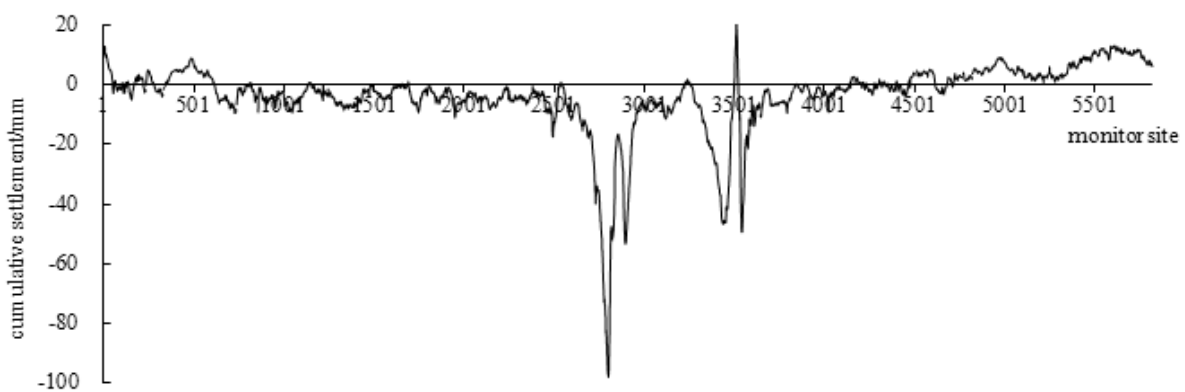

Figure 3. Graph of cumulative settlement of C from 2008 to 2010.

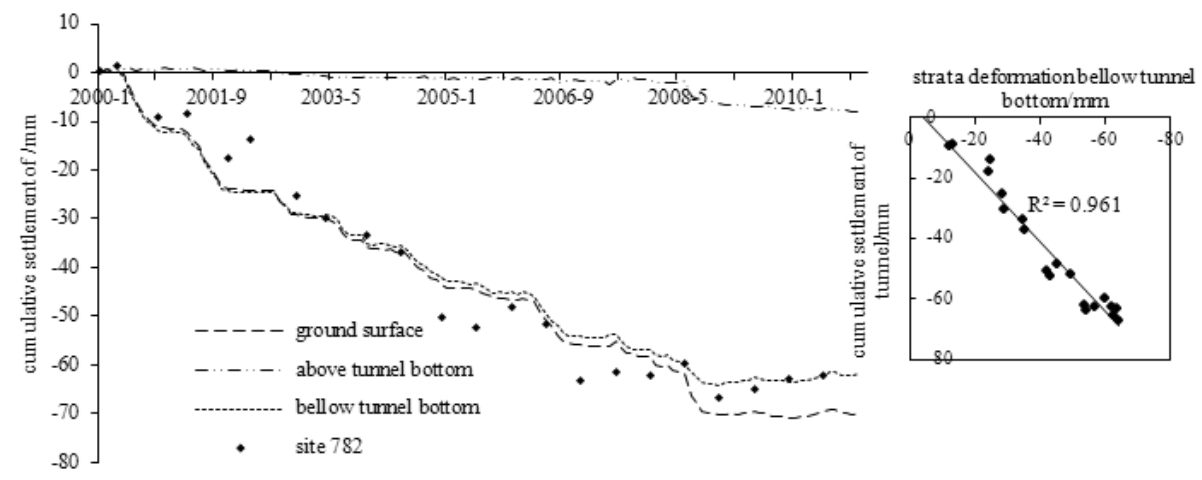

Figure 4. Contrast the monitoring results of point 782 with the ones of extensometer. 

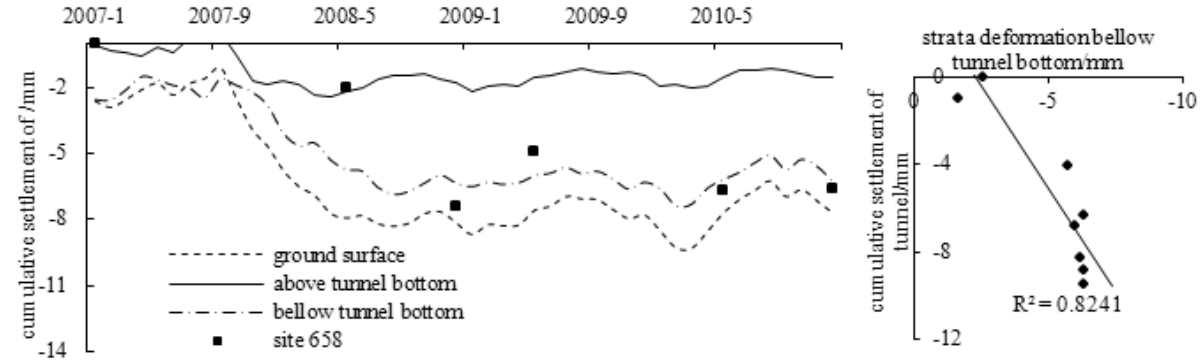

Figure 5. Contrast the monitoring results of point 658 with the ones of extensometer.

$60 \mathrm{~mm}$, while the soil compression below the tunnel floor was about $62 \mathrm{~mm}$. Also Site 658 had the similar compression, which produced $-2.6 \sim-7.3 \mathrm{~mm}$ of settlement while compression in the adjacent soils was $-1.5 \sim-7.4 \mathrm{~mm}$ (Fig. 5).

\section{Factors for rail settlement}

\subsection{Geological differences}

Tunneling and structure differences of underlying soil are important factors influencing the settlement of the rail way (Shi, 2010; Yan and Shi, 2006). By analyzing the subsidence characteristics of operating lines, we found that tunnels, which passed through shallow sand and ancient river formations, often had large and obvious settlement. In addition, if there are thick soft clays underlying the rail tunnel, it would grow into subsidence bowl along the entire line. For example, Line C passes through a length of sandy soil, whose thickness is about $10-15 \mathrm{~m}$. When trains pass, pore water in the sandy soil is prone to leakage from soil to tunnel. Subsequently, settlement in this area arises.

\subsection{Regional land subsidence}

As an underground structure in urban environment, subway tunnel is linear throughout the soft soil below the surface. So geological changes caused by urban activities would inevitably affect the subway tunnel. The regional land subsidence, resulting from groundwater exploitation and construction activities, forced the passing tunnel to give similar deformation features.

The cumulateve settlement curve of the subway and surface leveling-points along the Line are compared in Figs. 6 and 7. It is apparent that the two settlement characteristics are in agreement. When the amount of surface subsidence is large, the settlement of subway tunnel is also large. Thus, regional land subsidence along the subway directly affects the overall trend of tunnel settlement, which has become one of important factors for rail risk.

\subsection{Surrounding construction}

The trend of surrounding construction activities has a negative impact on rail settlement. For example, the excavation and contruction of a mallbegan on 28 September 2008, close to Line $\mathrm{C}$, while the dewatering well associatied with the development commenced pumping on 22 April 2009. On 27 December 2009, the foundation pit construction of the main building was completed. Monitoring results in Fig. 8 show that, from June 2009 to December 2009 tunnel sedimentation rate suddenly increased, which produced a total settlement of -60 to $-80 \mathrm{~mm}$. This is closely related to the mall's dewatering activities. When pit construction was completed, the rail sedimentation rate was drastically reduced.

Nearby pit construction would cause the outside soil to release stress during soil excavation, and the tunnel would produce horizontal and vertical displacements. In the process of reliving and dewatering constructions, the groundwater seepage changed, and the aquifer pressure was reduced. Then the pore water pressure in clayey soil layers decreased, which caused further consolidation of clay layers. The joint effect resulted in soil deformation and caused rail settlement. Therefore, this region should be focused as a high-risk zone when large construction activities take place near the tunnel.

\subsection{Structural differences}

Due to long-term monitoring of the operating lines, it was found that structural differences also have contributed to zone settlement. These special sections, for example, aisles connecting the tunnels and transition-section between underground and above-ground lines, are structuraly different with regard to their connecting pieces, which creates large changes of stress in the soil layer or tunnel body. After a period of operation, these sections grew up with dislocation and partial leakage, followed by longitudinal settlement.

\section{Management for prevention of rail settlement}

In order to ensure safe operation of Shanghai rail system, the Shanghai administrative department collaborated with major engineering and management units, and established a moni- 


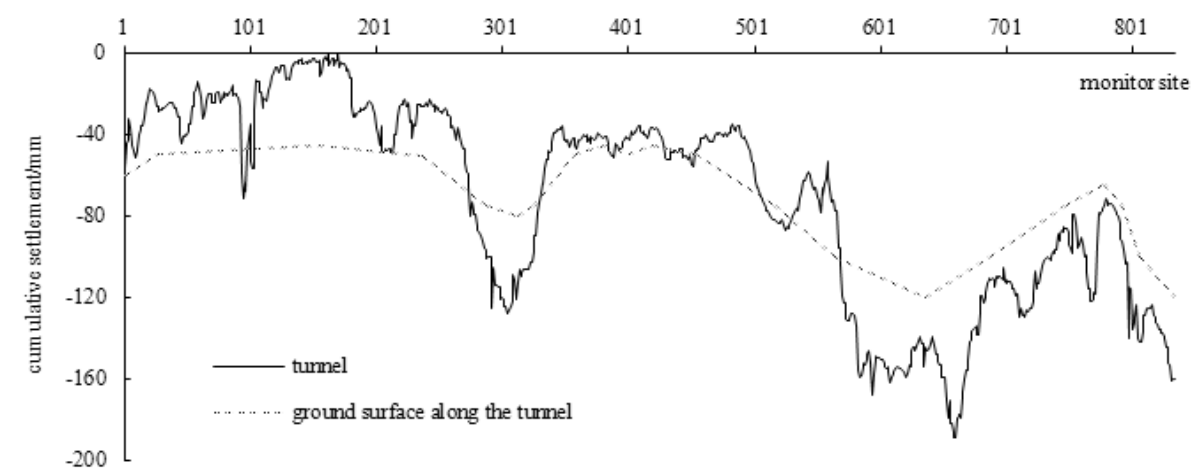

Figure 6. Graph of tunnel settlement and land subsidence along A from 1995 to 2000.

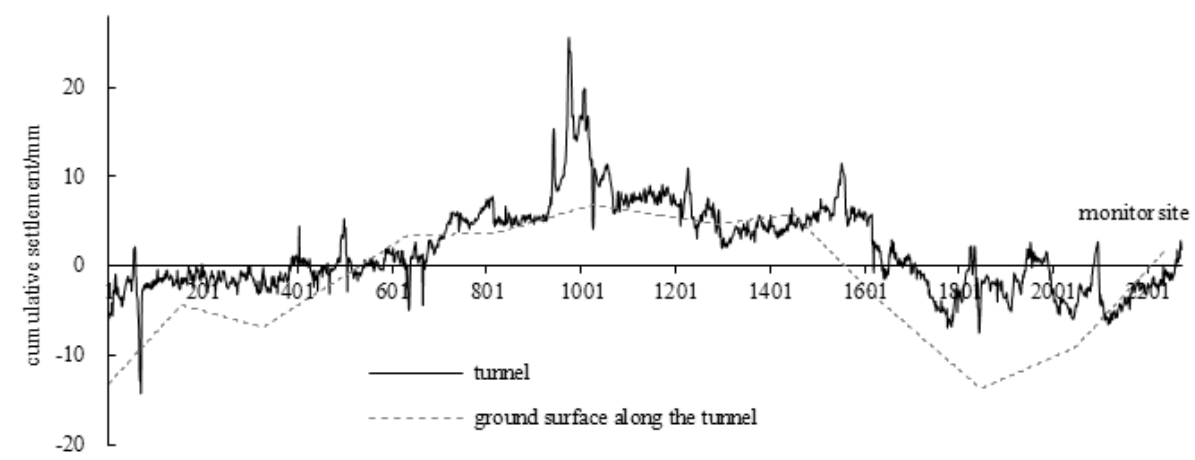

Figure 7. Graph of tunnel settlement and land subsidence along B in 2009.

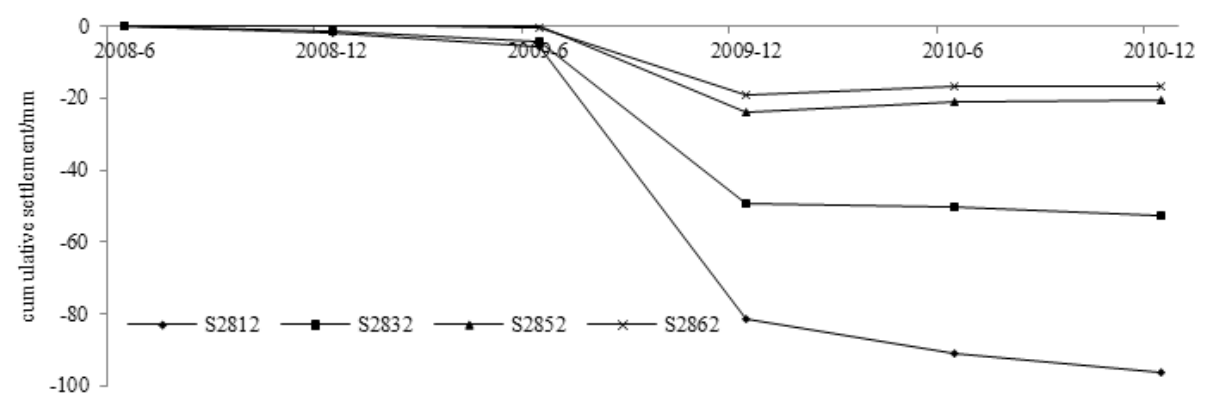

Figure 8. Duration curve of cumulative settlement in typical C sites nearby the pit.

toring and early-warning mechanism for major facilities' settlement. It included the following:

1. Regular meeting: regular meetings would be convened to discuss the dynamic data of major facilities' settlement, draw up monitoring plans, and discuss information sharing and other related matters.

2. Network construction: the two entities define their duties regarding-network construction, according to Shanghai Plan for Controlling and Management of Land Subsidence. This includes improving the monitoring network and optimizing the monitoring sites combined with municipal spatial layout of all major facilities.
3. Settlement monitoring: the Shanghai administrative department oversees the monitoring of regional and other settlements that occur along the major facilities. The frequency of investigation is not less than once a year. However, the engineering or management units should monitor their responsible projects, and report results to the administrative department. Monitoring frequency is made by each unit in accordance with safe operation of major facilities.

4. Information sharing: a data system is established. The two units create a uniform standard for data collection for major facilities' settlement, and all of the data will be put into the system, and shared by each unit. 
5. Early-warning mechanism: Shanghai administrative departments collect monitoring results, analyze and work on a regular summary report, which will be offered to facility-operating units in a timely manner. When the monitoring values of land subsidence along major facilities exceeds the control requirements, the administrative department will immediately inform the operational unit and share each data to find the problems and take steps toward mitigation.

\section{Conclusions}

Shanghai has operated metro lines for over 20 years. By means of continuous learning and research, some rules of rail settlement have been discovered. In this paper, we briefly illustrate the contributing factors, including operating time, geological conditions, structural differences, and external construction. In addition, a monitoring and early-warning system was established, which aims to reduce negative impacts on the rail transit system and brings greater security to the public.
Acknowledgements. The authors thank their colleagues for continuing support.

\section{References}

Chen, J. W. and Zhan, L. X.: Deformation measuring of the metro tunnel and deformation data analysis of shanghai metro line, Shanghai Geology, 21, 51-56, 2000.

Shi, Y. J.: Engineering geological conditions and major geological problems during construction of metro tunnels in Shanghai area, Journal of Engineering Geology, 18, 774-780, 2010.

Yan, X. X. and Shi, Y. J.: Structure characteristic of engineering geology in Shanghai, Shanghai Geology, 26, 51-56, 2006.

Wang, R. L.: Factors influencing deformation of shanghai soft soil metro tunnel and deformation analysis, Underground Engineering and Tunnels, 1-6, 2009.

Wang, Y. and Hang, H. W.: Hierarchy-Fuzzy Comprehensive Judgment for Safety Evaluation of Metro Running Tunnel, Underground Space, 24, 301-305, 2004. 